ORIGINAL ARTICLE

\title{
Short-term Results of Interlocking Nailing in Open Tibial Fracture
}

\author{
Khaled Mohammed Hasan I, Hosam Mohammed Khairy I, Mohammed El-Sadek Attia I, and \\ Saqar Khalleefah Saqar ${ }^{\text {II* }}$ \\ I: Department of Orthopedic Surgery Faculty of Medicine - Zagazig University, Egypt. \\ II: Department of Orthopedic Surgery, Faculty of Medicine, Tripoli University. Libya
}

\section{* Corresponding Author:}

Saqar Khalleefah Saqar

Department of Orthopedic

Surgery, Faculty of Medicine,

Tripoli University. Libya

Email:

Saqr89.saq@gmail.com

Submit Date: 01-04-2019

Revise Date: 05-05-2019

Accept Date: 06-05-2019

\begin{abstract}
Background: Tibial fractures are the most common long bone fractures, with around $25 \%$ being open fractures. The majority of open tibial fractures result from high velocity trauma such as road traffic accidents and falls from height. The management of these fractures can be complex due to the relative lack of soft tissue coverage and blood supply of the tibial shaft, The aim of this study to evaluate the short-term results of the tibial nailing in the open tibial fractures. Methods: This study included 20 patients admitted to Zagazig University Hospitals with open tibial fractures of different causes and classified according to Gastilo and Anderson classification and Orthopedic Trauma Association (OTA) Written informed consent was obtained from all participants and the study was approved by the research ethical committee of Faculty of Medicine, Zagazig University. The work has been carried out in accordance with The Code 4385/13-22018 of Ethics of the World Medical Association (Declaration of Helsinki) for studies involving humans. , Age above 18 years. Results: In our results, overall mean time to union was 5.47 months. the over all mean time to union was 36.7 weeks; in the type III cases, we had an average time to union of 7 months and a $10 \%$ incidence of infections. These results suggest that the nailing in open fractures of the tibia has faster union rates and lower rates of infections ?. Our results show that the aggressive management of the severe open fractures among the tibial fractures is effective. We accept that this approach is radical and that it has been claimed that an immediate soft tissue coverage is not safe. However, the analysis of our results showed good union rates and low rates of infections, thus supporting the concept that a delay is not necessary if the healthy soft tissues can be imported reliably into the zone of the injury. Conclusion: The treatment of open tibial shaft fracture has evolved over the last two decades. Improved wound care, newer generation antibiotic and better metallurgy for the implants have contributed to this change.
\end{abstract}

\section{INTRODUCTION}

$\mathrm{T}$ ibial fractures are the most common long bone fractures, with around $25 \%$ being open fractures. The majority of open tibial fractures result from high velocity trauma such as road traffic accidents and falls from height. The management of these fractures can be complex due to the relative lack of soft tissue coverage and blood supply of the tibial shaft [1].

Intramedullary interlocking nails are very commonly used in trauma practice for tibial fractures; however, conditions such as nonunion, reoperations to dynamize the nail, interlocking screw failure, and proximal nail migration are still frequently encountered problems [2].

In surgical treatment of tibial shaft fractures, compression of interlocking nails provides more stability. However, screw deformation and subsequent early locking screw failure may occur as a result of the excessive compression effect [3]. 
The treatment of open fractures of the tibial shaft remains controversial. The precarious blood supply and the lack of soft tissue cover of the shaft of the tibia make these fractures vulnerable to infections and nonunion. The rate of infection may be as high as $50 \%$ in the grade III-B open fractures. Attempts which were made to reduce these complications have led to aggressive protocols which include immediate intravenous antibiotics, repeated soft tissue debridement, stabilization of the fractures, early soft tissue covers and prophylactic bone grafting [4].

The use of reamed intramedullary nails in the management of open tibial fractures is contentious. While reamed nails offer an improved stability to the fractures, their use carries the theoretical risks of increasing infections and nonunion as a consequence of the disturbed endosteal blood supply. The use of unreamed intramedullary nails may compromise the stability at the site of the fractures. The numerous methods which are used for treating open fractures of the tibia are an evidence of the ongoing efforts which are being made to improve the outcomes of the treatment of these fractures and of the continuing pursuit of more efficient and advanced methods for treating these fractures [5].

\section{METHODS}

This clinical trial study was performed in the period from March 2018 to November 2018 in Orthopedic Surgery Department of Zagazig University Hospitals.

This study included 20 patients admitted to Zagazig University Hospitals with open tibial fractures of different causes and classified according to Gastilo and Anderson classification and Orthopedic Trauma Association (OTA). Written informed consent was obtained from all participants and the study was approved by the research ethical committee of Faculty of Medicine, Zagazig
University. The work has been carried out in accordance with The Code 4385/13-2-2018 of Ethics of the World Medical Association (Declaration of Helsinki) for studies involving humans.

Inclusion criteria: All patients with Interlocking Nailing in Open Tibial Fracture age Age above 18 year.

Exclusion criteria: Open Tibial fracture treated primarily with external fixation. ,Non union of tibial fractures. ,Intra-articular fractures. ,Closed tibial fractures. And Grade IIIC fractures

Clinical examination carried out regarding the neurological examination done to asses and document the sensory and motor function, vascularity in the affected limp including limp color warmth and palpation of peripheral pulses capillary refilling less than 3 seconds and fracture examination (type and presence of infection).

\section{RESULTS}

This study conducted on 20 patients with open tibial fractures of different causes and classified according to Gastilo and Anderson classification and Orthopedic Trauma Association (OTA)., In our results, overall mean time to union was 5.47 months. presented their results on 51 type III open tibial fractures which were treated with external fixations. The overall mean time to union was 36.7 weeks

$10 \%$ were diabetic and $45 \%$ were smoker as shown in table (2). GA were distributed as (I 45\%, II $25 \%$ and III $30 \%$ ), while OTA was distributed as A2 50\% and B1 50\% all cases handled with MDN Nail and with static locking, regarding coverage methods majority were DP7 $45 \%$ Followed by DP4 35\%.as seen in table (3).

3 cases fail to union, regarding union time 9/17 cases wich success to union take 5 month and the rest 6 month as shown in table (4), fig (2).

Table 1. Age and sex distribution among studied group $(\mathrm{N}=20)$

\section{Age}

\begin{tabular}{|l|l|}
\hline Mean \pm SD & $29.0 \pm 6.48$ \\
\hline Median $($ Range $)$ & $27.0(19-42)$ \\
\hline Sex & \\
\hline Male 20/20 (100.0\%) & \\
\hline
\end{tabular}


Table 2. Personal characters and history distribution among studied group

\begin{tabular}{|l|l|l|l|}
\hline Co morbidity & NO & N & $\%$ \\
\hline Smoking & DM & 2 & 90.0 \\
\hline & No & 11 & $\mathbf{1 0 . 0}$ \\
\hline & Smoker & 9 & $\mathbf{5 5 . 0}$ \\
\hline & Total & $\mathbf{2 0}$ & $\mathbf{1 0 0 . 0}$ \\
\hline
\end{tabular}

$10 \%$ were diabetic and $45 \%$ were smoker

Table 3. Fracture characters distribution among studied groups

\begin{tabular}{|c|c|c|c|}
\hline & & $\mathbf{N}$ & $\%$ \\
\hline \multirow[t]{3}{*}{ GA } & I & 9 & 45.0 \\
\hline & II & 5 & 25.0 \\
\hline & III & 6 & 30.0 \\
\hline \multirow[t]{2}{*}{ OTA } & A2 & 10 & 50.0 \\
\hline & B1 & 10 & 50.0 \\
\hline \multirow[t]{5}{*}{ Coverage } & DP4 & 7 & 35.0 \\
\hline & DP6 & 2 & 10.0 \\
\hline & DP7 & 9 & 45.0 \\
\hline & DP8 & 2 & 10.0 \\
\hline & Total & 20 & 100.0 \\
\hline
\end{tabular}

Table 4. Success of union distribution among studied group

\begin{tabular}{|c|c|c|c|c|}
\hline & & & $\mathbf{N}$ & $\%$ \\
\hline Union & & Success & 17 & 85.0 \\
\hline & & Failure & 3 & 15.0 \\
\hline Union time & & 5 month & 9 & 45.0 \\
\hline & & 6 month & 8 & 40.0 \\
\hline $\begin{array}{l}\text { Mean } \pm \text { SD } \\
\text { Median (range) }\end{array}$ & $\begin{array}{l}5.47 \pm 0.51 \\
5.0(5-6)\end{array}$ & Fail to union & 3 & 15.0 \\
\hline Total & & & 20 & 100.0 \\
\hline
\end{tabular}


Table 5. Relation of clinical characters with success to union

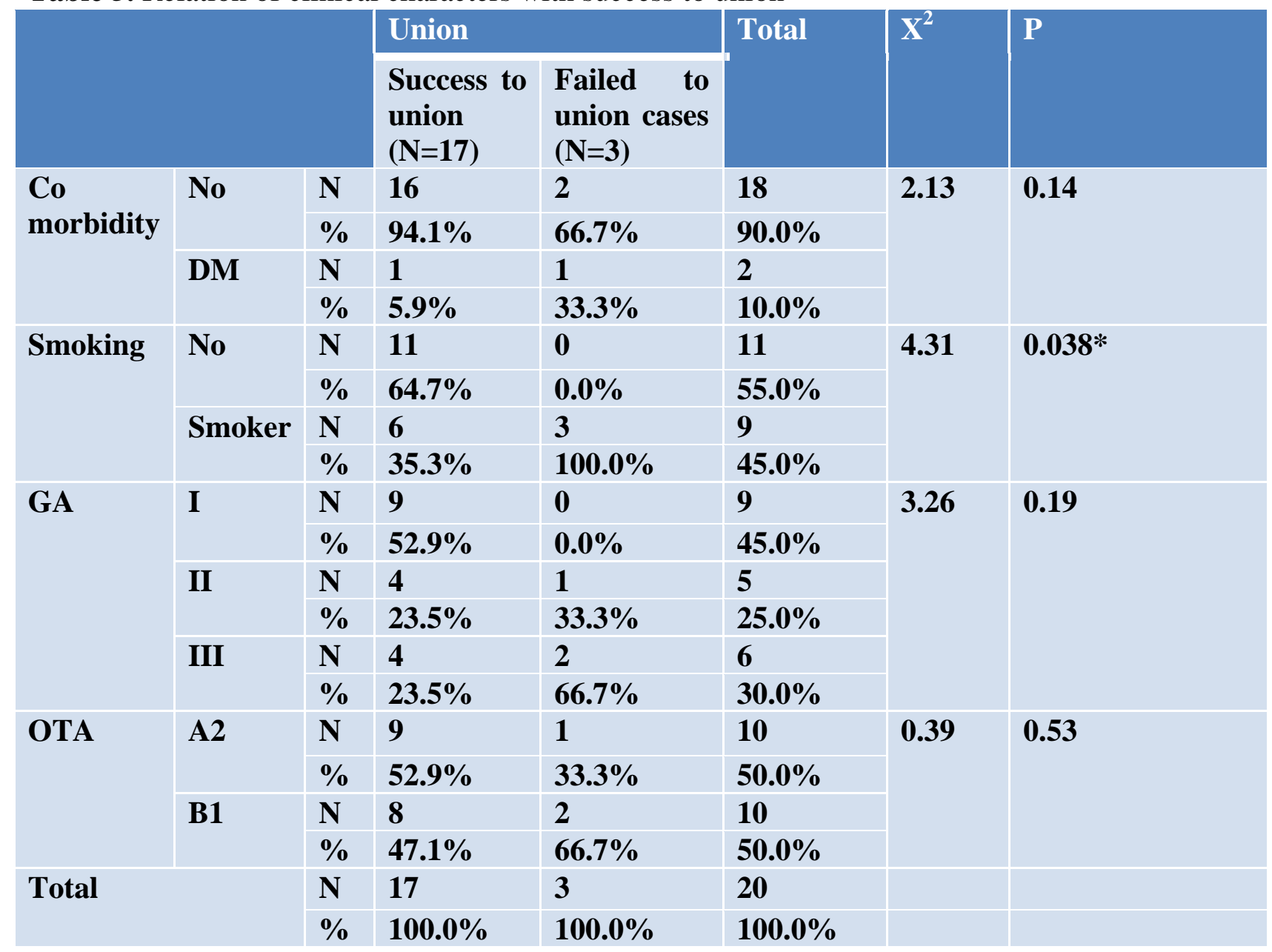

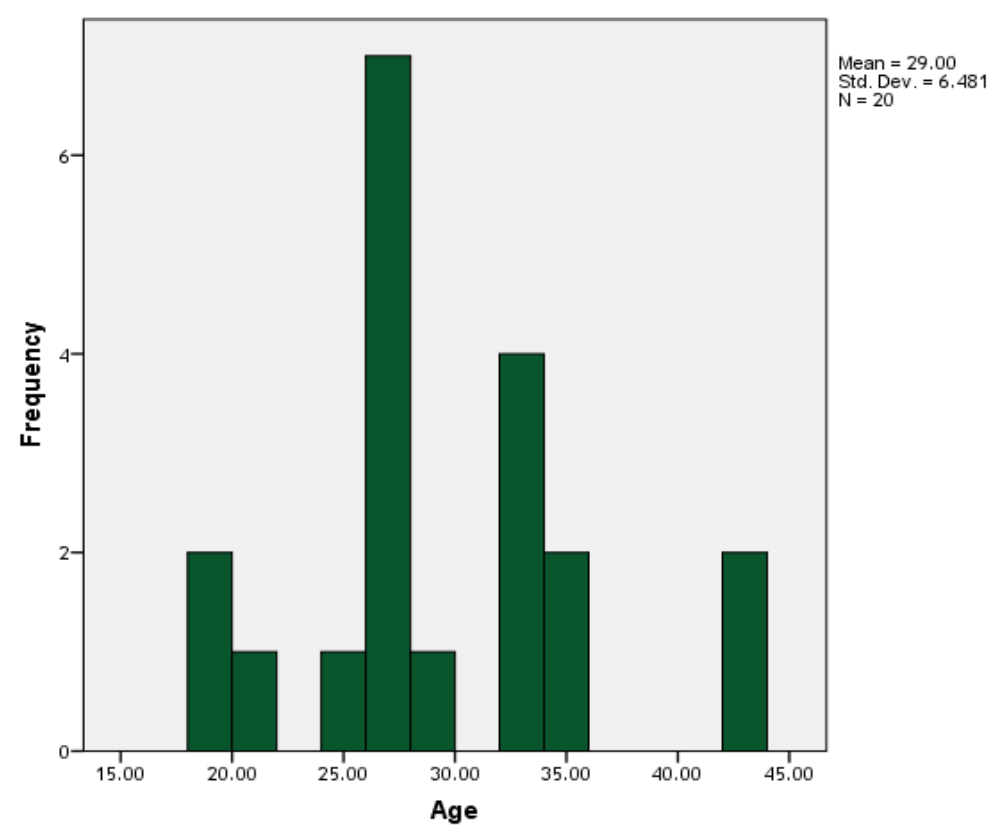

Figure 1. Age and sex distribution among studied group ( $\mathrm{N}=20)$ 


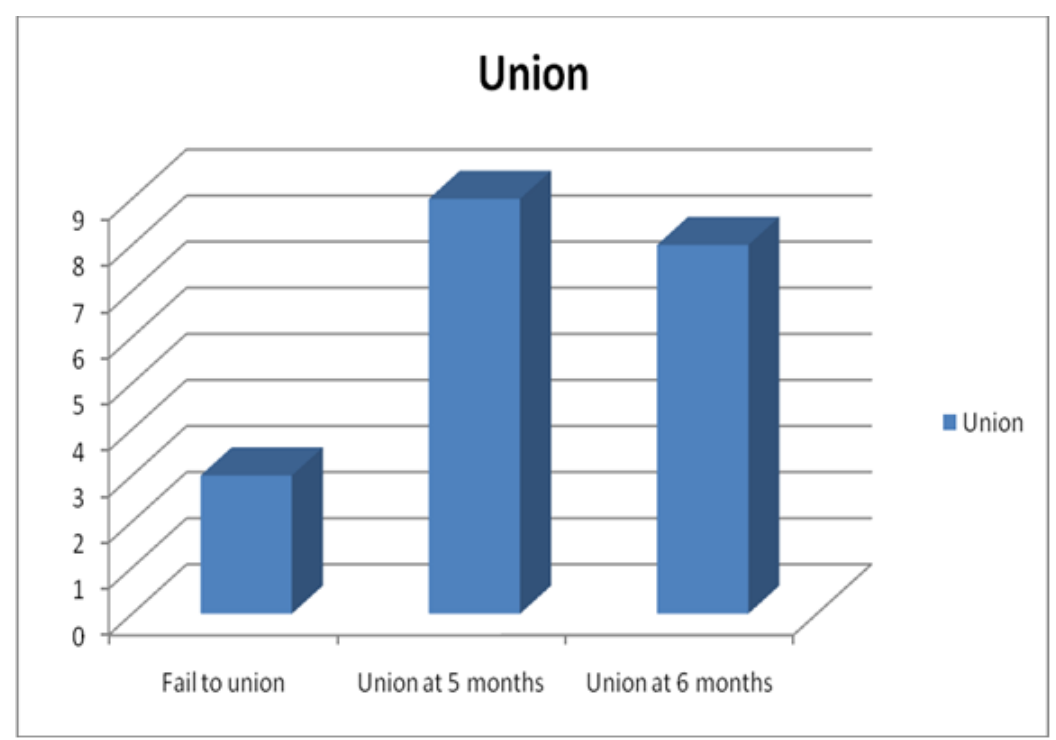

Figure 2. Success of union distribution among studied group

\section{DISCUSSION}

The tibial shaft is one of the most common sites of open fractures [6]. The specific methods of skeletal stabilization and soft tissue treatment of open fractures continue to be topics of debate in the orthopaedic traumatology [7]. Of all the open fractures, $63 \%$ are seen in the tibia alone [8].

Open tibia fractures continue to have a high infection rate, reported to be $10-50 \%$ in the literature, despite advances in wound care, soft tissue cover and types of internal and external fixator devices[7].

In our results, overall mean time to union was 5.47 months. Steinberg et al. [9] studied 25 patients of open tibial fracture with average union time of 15.4 weeks with no infection, malunion, non-union or delayed union. . In our series, in the type III cases, we had an average time to union of 7 months and a $10 \%$ incidence of infections. These results suggest that the nailing in open fractures of the tibia has faster union rates and lower rates of infections which also has been supported by the results of other similar studies[10].

This further reinstated that although antibiotics are helpful, it is generally agreed that they are no substitute for an adequate debridement. If a prolonged period passes between the injury and the attempts which are made towards a soft tissue reconstruction, the wound may well become contaminated or infected in spite of the surgeon's best efforts [11]. Leaving the debrided wound open to allow wound healing by a secondary intention was the standard treatment prior to World War II, but since then, a delayed primary closure or a split thickness skin graft at five to seven days have proved to be safe and effective methods of the wound management after the initial debridement in both civilian and military injuries [12].

Regaining the length of the traumatized and the swollen muscles after intramedullary nailing with intact or partially ruptured fascial envelopes may elevate the compartmental pressure. Blick et al., [13] reported a 9.1\% incidence of the compartment syndrome in open fractures which were treated by intramedullary nailing. We had one case in which a fasciotomy was done due to a high compartmental pressure. The low incidence of the compartmental syndrome may be because we had always closed the wounds with loose stitches and had never closed the fascial compartments.

In our series, Anterior Knee Pain was observed in 20\% cases. Muhammadet al., [14] reported a $36 \%$ incidence of anterior knee pain and they advocated the techniques of using a more proximal and medial entry point, hyper flexing the knee during the nail insertion and extending the knee during the screw insertion to lessen the irritation of the overlying tendons.

[15]

The major factors which affect the prognosis of open tibial fractures after high- energy 
trauma, are the severity of the soft tissue injury, the degree of contamination, the fracture configuration and the extent of the comminution. In the presence of significant trauma to the local tissues, any operative intervention such as a plate or a screw fixation can further devitalize the already compromised tissues. Therefore, it is extremely important to avoid such operative interventions for preventing sepsis and for promoting the healing of the tibial fractures [16].

Our results show that the aggressive management of the severe open fractures among the tibial fractures is effective. We accept that this approach is radical and that it has been claimed that an immediate soft tissue coverage is not safe. However, the analysis of our results showed good union rates and low rates of infections, thus supporting the concept that a delay is not necessary if the healthy soft tissues can be imported reliably into the zone of the injury[17].

Overall, these results show that in the grade I and II open tibial fractures, a primary unreamed intramedullary nailing can be safely done, with minimal complications and excellent functional results. For the grade III open fractures of the tibia, the modern techniques of management, combined with the skills of experienced orthopaedic and plastic surgeons, can consistently restore excellent limb functions in a very high proportion of patients. In some of the most severely injured limbs, a salvage is possible and a useful functional limb can be obtained, as was shown in our study[18].

It is important to analyze such cases of compound injuries when they come to us in emergency. Such cases should be taken up only if the centre has both orthopaedic and plastic surgeons' skills available and then a fairly good outcome can be expected.

The Gustilo-Anderson classification has been commonly used in guiding treatment and predicting outcomes of open fractures. Despite some questions about its limited interobserver agreement, it is still the most useful tool to evaluate open fractures. This study has similarly found a strong correlation between the Gustilo classification of injury of open tibial fractures and the development of complications, which corroborates with current literature. This further highlights the need for increased vigilance, monitoring and regularity of follow-up for patients with a high grade Gustilo injury post-surgical fixation $[19,20]$.

The time to fixation after an open tibial fracture has been the subject of continued debate in literature. Choudry et al noted that in patients with Gustilo IIIb fractures, early fixation $(<1$ week) was associated with a nonunion rate of $42 \%$. This was in contrast to a rate of $74 \%$ in patients who had surgery later than 1 week from presentation. Gopal and Tropet independently found that the rate of complications was lower in patients who had soft tissue reconstruction done within 72 hours. They concluded that injuries with less severe soft tissue trauma are more amenable to earlier soft tissue coverage operations, reducing the risk of osteomyelitis[21].

However, Franken et al demonstrated that there was no significant difference in the rate of bony complications between groups with early (<72 hours) and delayed fixation 15. Karanas et al went on to demonstrate that soft tissue coverage could be performed safely and effectively in the delayed period ( $>72$ hours) with a complication rate of only $7.1 \% 16$. This study also showed that the rate of infective and bony complications was not significantly affected by the time taken from injury to fixation. Alas, while it is accepted that good results can be achieved even with a delay between injury to fixation, it has to be noted that these results were achieved with optimal wound care and meticulous treatment planning[22].

In this study, the location of the fracture and time to surgery did not have a significant effect on the rate of complications, but trended towards it. This could be due to our study's sample size and larger studies are warranted to confirm this relationship[23,24]. Superficial infection usually resolves and respond well to iv antibiotic and wound dressing. Our study show no result of deep infections. . Multiple studies reported superficial infection rates following intramedullary nailing of open tibial fractures 
Study of Larsen et al. [25] in operative treatment of open tibia fracture showed infection rate of $13 \%$. while the results in this study show a superficial infection in 2 patient with rate of $13.3 \%$ and treated with IV antibiotic .

Traditionally, empirical antibiotic prophylaxis has involved the use of first-generation cephalosporins such as cefazolin (1-2g, 6-8 hourly) for Gram-positive coverage in Gustilo-Anderson type I fractures. An aminoglycoside such as gentamycin $(120 \mathrm{mg}$, 12 hourly) is added in higher grade injuries for Gram-negative coverage. Additionally, metronidazole $(500 \mathrm{mg}, 12$ hourly) or penicillin (1.2g, 6 hourly) can be added for coverage against anaerobes[26].

Radiographic union was defined as evidence of bridging of three of the four cortices in standard anteroposterior and lateral radiographs. most authors have considered non-union to be a stage in which no signs of union can seen at six months and there is no further progression in the consolidation process during three consecutive months (27) The RUST score is a novel fracture assessment tool that was developed to help standardize the radiographic assessment of tibial fractures. Whelan et al, (28) They demonstrated that the RUST score is a reliable assessment tool of fracture healing with good agreement among five observers (intraclass correlation of 0.86 ).

Radiographic union scale in tibial fractures (RUST) score by Whelan et al, which use as radiographic signs to assess healing. In our series the Rust score was distributed as 11.26 \pm 0.96 with minimum 9 and maximum 12. while Erturer et al. (29), In his study, reviewed the radiographic results and functional outcomes Using the RUST scale, they have reported good union rates accounting for all 139 patients included in the sample population, with rust scores ranging from 8 to 12 .

\section{CONCLUSION}

The treatment of open tibial shaft fracture has evolved over the last two decades. Improved wound care, newer generation antibiotic and better metallurgy for the implants have contributed to this change. Now, the present trend in the management of such fractures is primary wound debridement, skeletal stabilization and primary soft tissue cover. we also conclude that sequential protocol for treating exposed tibial shaft fractures of Gustilo and Anderson Grade I, II and IIIA comprising initial treatment with thorough debridement, IV antibiotics and bony stabilization followed by osteosynthesis with intra medullary interlocking nailing, presented with high consolidation rates and low nonconsolidation and infection rates.

Conflict of Interest: Nothing to declare.

Financial Disclosures: Nothing to declare. REFERENCES

1) Drake R; Wayne V, Mitchell A. Gray's Anatomy for Students (2nd ed.). pp. 558-560. ISBN 978-0-443-06952-9. 2010.

2) Karaarslan AA, Acar N, Aycan H, and Sesli E. The functional results of tibial shaft fractures treated with intramedullary nail compressed by proximal tube. Strategies in Trauma and Limb Reconstruction. 2016; 11(1), 25-29.

3) Rytter S, Egund N, Jensen LK, Bonde JP. "Occupational kneeling and radiographic tibiofemoral and patellofemoral osteoarthritis". J Occup Med Toxicol. 2009; 4 (1): 19.

4) Gill TJ, Van de Velde SK, Wing DW, Oh LS, Hosseini A, Li G. "Tibiofemoral and patellofemoral kinematics after reconstruction of an isolated posterior cruciate ligament injury: in vivo analysis during lunge". Am J Sports Med. 2009; 37 (12): 2377-2385.

5) Agrawal A, Chauhan VD, Maheshwari RK, and Juyal AK. Primary Nailing in the Open Fractures of the Tibia-Is it worth?. Journal of clinical and diagnostic research: JCDR. 2013; 7(6), 1125.

6) Gustilo RB, Mendoza RM, and Williams DN. Problems in the management of type 3 (Severe) open fractures: a new classification of type 3 open fractures. J Trauma. 1984; 24: 742-46.

7) Rhinelander FW. Tibial blood supply in relation to fracture healing. Clin Orthop. 1974; 105: 3481.

8) Fairbank AC, Thomas D, Cunningham B, Curtis M, and Jinnah RH. Stability of reamed and unreamed intramedullary tibial nails: a biomechanical study. Injury. 1995; 26: 483-85.

9) Steinberg EL, Geller DS, Yacoubian SV, Shasha N, Dekel $S$, Lorich DG. Intramedullary fixation of tibial shaft fractures using an expandable nail: early results of 54 acute tibial shaft fractures. S Orthop Trauma. 2006; 20:303-9.

10) Pandurangaiah $S$ and Shaikh B. Analysis of primary interlocking nailing for open fractures of tibial shaft. International Journal of Orthopaedics Sciences. 2017; 3(4): 95-101. 
11) Green SA. Salvage of Infected Periarticular Fractures. In Advanced Techniques in Limb Reconstruction Surgery (pp. 119-134). Springer, Berlin, Heidelberg. 2015.

12) Halawi MJ and Morwood MP. Acute management of open fractures: an evidence-based review. Orthopedics. 2015; 38(11), e1025-e1033.

13) Higgins TF, Klatt JB, and Beals TC. Lower Extremity Assessment Project (LEAP)-the best available evidence on limb-threatening lower extremity trauma. Orthopedic Clinics. 2010, 41(2), 233-239.

14) Muhammad A, Syed $K$ and ZakiIdress. Anterior Knee Pain After Intramedullary Tibia Nailing in A Muslim Society: A Prospective Randomized Study Comparing Two Different Nail Insertion Techniques. JPOA. 2017; Vol. 29 (2) :11-15

15) Smith PW, Bennett G, Bradley S, Drinka P, Lautenbach E, Marx J, et al. SHEA/APIC guideline: infection prevention and control in the long-term care facility. Infection Control \& Hospital Epidemiology. 2008; 29(9), 785-814.

16) Lua JYC, Tan VH, Sivasubramanian H, et al. Complications of Open Tibial Fracture Management: Risk Factors and Treatment. Malaysian Orthopaedic Journal. 2017; 11(1): 1822.

17) Klein P, Schell H, Streitparth F, Heller M, et al. The initial phase of fracture healing is specifically sensitive to mechanical conditions. J Orthop Res. 2003; 21(4):662-669.

18) Klemm $K$ and B6rner M. Interlocking nailing: extended scope of application for Kantscher nails. Med Focus. 1985; 6:10- 13

19) Browner BD, Jupiter JB, Krettek C, and Anderson PA. Skeletal Trauma E-Book. Elsevier Health Sciences. 2014.

20) Papakostidis C, Kanakaris NK, Pretel J, Faour O, Morell DJ, and Giannoudis PV. Prevalence of complications of open tibial shaft fractures stratified as per the Gustilo-Anderson classification. Injury. 2011; 42(12), 1408-1415.
21) Lua, JYC, Tan VH, Sivasubramanian H, and Kwek EBK. Complications of Open Tibial Fracture Management: Risk Factors and Treatment. Malaysian orthopaedic journal. 2017; 11(1), 18.

22) Ronga M, Longo UG, and Maffulli N. Minimally invasive locked plating of distal tibia fractures is safe and effective. Clinical Orthopaedics and Related Research. 2010, 468(4), 975-982.

23) Shuler TE. Adult trauma. Miller MD, ed. Review of Orthopedics. Philadelphia: WB Saunders; 1996. 350-393.

24) Kindsfater K, Jonassen EA. Osteomyelitis in grade II and III open tibia fractures with late debridement. J Orthop Trauma. 1995; Apr. 9(2): 121-127.

25) Larsen L, Madsen J, Hoiness P. Should insertion of intramedullary nails for tibial fractures be with or without reaming? A prospective, randomized study with 3.8 years' follow-up. J Orthop Trauma. 2004; 18:144-149.

26) Brumback RJ, Jones AL. Interobserver agreement in the classification of open fractures of the tibia. The results of a survey of two hundred and forty-five orthopaedic surgeons. J Bone Joint Surg Am. 1994; 76(8): 1162-1166.

27) Rosenthal RE, MacPhail JA, and Oritz JE. Non-union in open tibial fractures. J Bone Joint Surg. 1977; 59-A: 244-248.

28) Whelan DB, Bhandari M, Stephen D, Kreder H, McKee MD, Zdero R, et al. Development of the radiographic union score for tibial fractures for the assessment of tibial fracture healing after intramedullary fixation. J Trauma. 2010; 68: 629632.

29) Erturer, Ozturk I, Dirik Y, Uzun M, Aksoy B. Radiographic and functional results of osteosynthesis with locked unreamedintramedullary nailing of femoral shaft fractures in adults. Acta Orthop Traumatol Turc. $2005 ; 39(5): 381-386$.

saqar, S., hassan, K., Khairy, H., 2019) (الصادق, Short-term Results of Interlocking Nailing in Open Tibial Fracture. Zagazig University Medical Journal, Jully. 2020 Volume 26 Issue 4 (548-555), -. doi: 10.21608/zumj.2019.10507.1177 